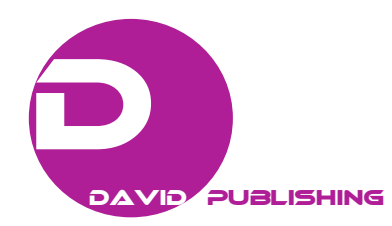

\title{
Urban Regeneration: Better Cities for Sustainable Development
}

\author{
Mahmoud Ali Alsubeh \\ Urban and Regional Planning Department, Faculty Of Environmental Design, King Abdulaziz University, Jeddah 21589, Saudi \\ Arabia
}

\begin{abstract}
With the increasing growing of the environmental issues and climatic change, sustainable urban development of cities became an urgent demand. Urban development relied on four pillars; the institutional, social, environmental and economic pillars. Urban regeneration is not a single concept; it is a group of strategies. This study concluded that those strategies include; the public action, certification programs and corporate responsibility theories.
\end{abstract}

Key words: Urban regeneration, sustainability, city.

\section{Introduction}

Industrial emissions, waste production, traffic congestion, poor air quality, noise and overcrowding are only a few of the several externalities concern contemporary urban consumption and production patterns. Cities are presently facing main challenges into their life's quality as well as to the opportunities' range, in which the urban environments have the ability to provide their residents. A particular individual has the ability to speak about three major families of confronts for the sustainable regeneration which is sustainable: institutional (geographic and governance), social (health, cohesion and inequality) and environmental (resource use, carbon emissions and climate change) $[1,2]$.

The fact of climate change represents specific challenges intended for the cities. Droughts, heat waves, flooding as well as the other extreme whether proceedings physically influence on the urban infrastructures and neighborhoods; thus, on the mortality and health of urban populations [3]. Moreover, they have the ability to influence in indirect way on the urban economies and communities

Corresponding author: Mahmoud Ali Alsubeh, associate professor, research fields: theories of architecture and restoration. E-mail: alsubeh36mah@gmail.com. throughout harm to the main assets as well as the uncertainty's creation concerning the future that with each other erode assurance within the financial and social capital [4].

Furthermore, socio-economic inequalities are supposed to be noticed as the main challenge to the sustainable regeneration, which is urban. Within an international context, the growing competition for the resources and energy is probable to connect for the influences of climate change to influence disproportionally on the most vulnerable and the poorest [5]. This is no less true within the cities, wherever inequalities are increasing because of the number of economic and demographic phenomena, particularly aged (with several aged individuals being less capable to cope with the impacts of environment) developing racial variety and increasing numbers of individuals experiencing social exclusion and/or poverty. These improvements are considered inter-related as well as join to generate various configurations of the environmental weakness within a particular city [6].

Organizational challenges to the urban sustainability are connected to stress among managerial, technical and top-down approaches in the direction of the urban regeneration as well as grassroots or bottom-up 
environmental initiatives, expectations and needs. It is extensively accepted that in the urban regeneration, processes of democratic societies are supposed to accept governance approaches which contain several stakeholders involving civil communities-of-interest as well as the residents [7]. Nevertheless, too frequently, we notice uncertain clashes among what local communities desire for their neighborhoods on one side and on the other side, the city administrations' plans. Besides, the commercial developers' corporate interests add for the mix that has the ability to generate lasting blockages within win-lose situations or decision-making [8].

In this study, we will study urban regeneration as the best method for sustainable development in cities. In this work, the mechanisms, challenges and opportunities facing sustainable urban regeneration will be reviewed in order to come up with plans to the best sustainable development in cities.

\section{Literature Review}

\subsection{Sustainable Urban Regeneration}

Generally, it is significant to explain the things we understand through the sustainable regeneration [9]. Whereas, a steady definition of sustainable urban development or urban sustainability has confirmed in order to be vague, in the most academic circles and policy, which is agreed that they have the ability to recognized as a combined four major pillars: institutional, social, environmental and economic (see Fig. 1) [10]. On the similar layer, the word "integrated sustainable approach” is mostly utilized to depict the incorporation of these various scopes of sustainable local improvement. Urban sustainability can be understood from the environmental pillar's direction, thus the urban sustainability that is environmental, whereas taking into account the connections with economic, institutional and social pillars [11].

Urban regeneration is considered as a way for upgrading and reorganizing existing spaces more willingly than proposing recent urbanization [12]. Urban regeneration is mainly interested in reinforcing the centers of the city before the industrial areas, inner/early ring suburbs as well as post war (post 1945), the areas of housing facing decline's periods because of intersecting and compounding pressures. Factors

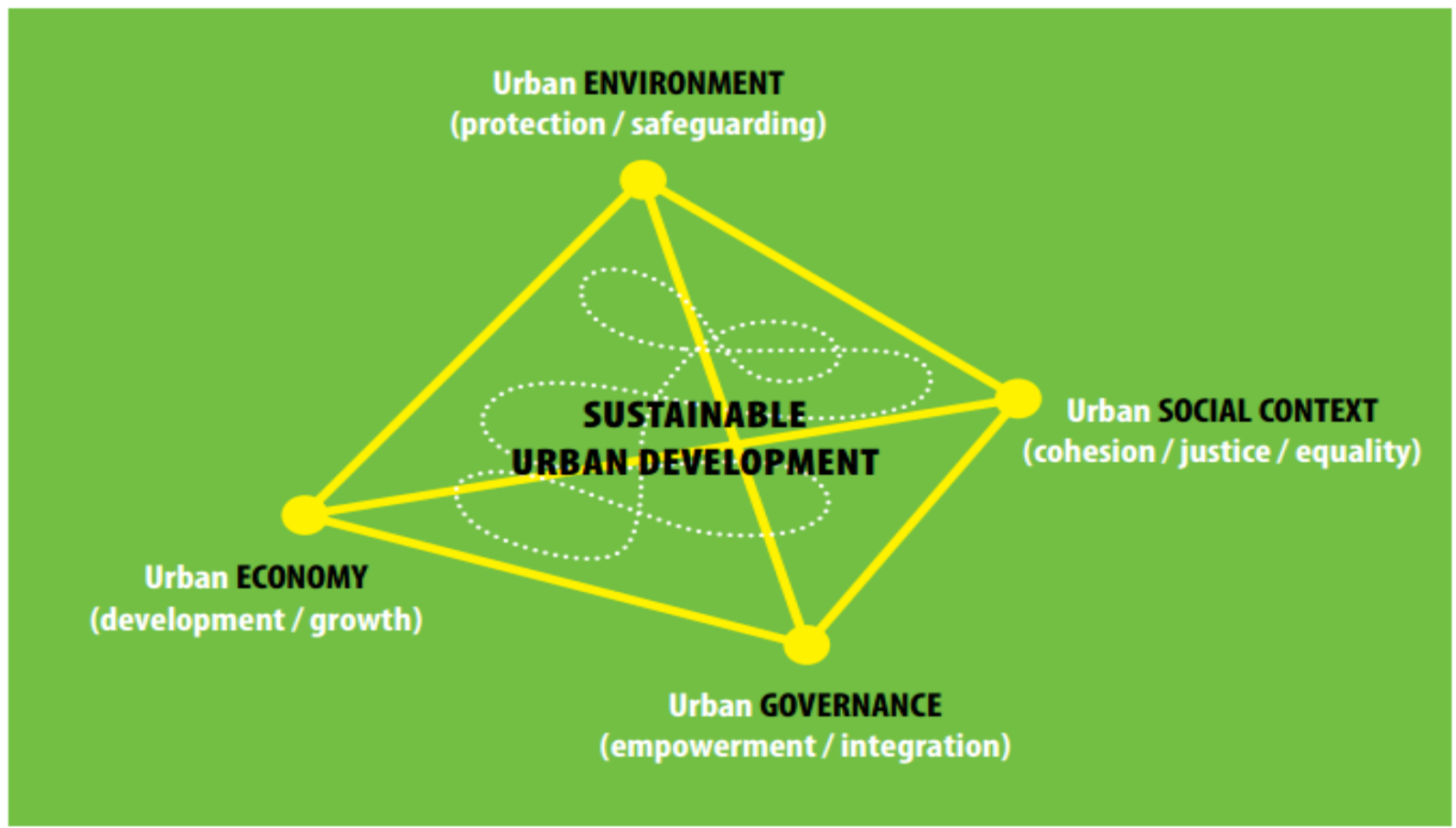

Fig. 1 Urban sustainability's prism [13]. 
concern the adoption of projects and regeneration policies involve pressures, the main long-term or short-term economic problems, physical changes, physical deterioration, social or ethnic tensions, political disenfranchisement, cyclical or structural employment issues, infrastructural obsolescence, underinvestment and demographic changes to the urban areas. Normally, the actions of urban regeneration contain environmental/physical, social and economic development measures within the areas under the intervention. Urban regeneration within the majority of its contributes in the direction of the implementation concerns the sustainable development during the "recycling" of buildings and land, lessening recent construction materials and demolition waste in addition to lessening the requests for marginal urban development as well as facilitating compactness and intensification of obtainable urban areas [10]. For that reason, we recognize sustainable urban regeneration the same as regeneration processes, policies and actions in a city that attend to consistent socio-economic, spatial and technical problems for lessening the environmental influence, lessen the environmental risk, as well as to develop the environmental quality of urban assets, lifestyles and systems [14].

Environmental actions within the urban regeneration are entrenched in the complicated policy/political, economic, geographical, cultural and social contexts. Moreover, environmental and successful actions are not only supposed to be precisely effectual; they are also supposed to respond to the conditions' series of sustainability concerning the exceeding contextual factors on the local scale, as well as to be standardized in order to accomplish effects vital for ensuring sustainability on the global scale. Moreover, we conceive that this particularity demands to be taken into consideration for evaluating the relative successes/merits of the tangible actions within particular contexts that based on a great extent on contradictory preliminary points. We utilized distinctions among "stepping-up” and "progressive" cities to demonstrate the level since they are at developing their regeneration actions' environmental sustainability [15].

Therefore, urban regeneration is defined in this study as a range of strategies or initiatives, encompassing and addressing a number of inter-related economic, social, environmental, institutional or physical aspects of urban areas [16]. In sum, areas in need of regeneration suffer from a weakened economic base, combined with high concentrations of unemployment and socially disadvantaged residents. These problems are often manifested in an area with a poor physical and environmental setting such as contaminated or derelict land and poor quality housing and amenities. This nexus of conditions can lead to poverty, crime and other problems [17].

Following from the above, we understand sustainable urban regeneration as regeneration policies and processes within a city, which seek to address inter-related problems in order to consider, reduce and mitigate their environmental impact. More specifically, the policies, plans and actions that urban actors implement to sustainably tackle regeneration issues have to be studied that have a strong environmental dimension whilst also addressing wider relationships of these aspects with other dimensions of sustainability. These policies, plans and actions can include the minimization of required inputs and of energy, water, food, materials, etc., and process outputs of waste, heat, air and water pollution, carbon emissions, etc. (see Table 1) [18].

\subsection{Cultural Quarters as Mechanisms for Urban Regeneration}

Table 2 summarizes the constituents once a particular individual would anticipate for finding within a victorious cultural quarter. These are provided, under the mentioned three sub-headings: meaning, form and activity. It is significant to assure that a high-quality cultural quarter would involve a single 
Table 1 Types of regeneration policies, plans and actions with a strong environmental dimension [18].

\begin{tabular}{ll}
\hline Type & Regeneration policies, plans and actions \\
\hline \multirow{2}{*}{ Energy } & Energy-efficiency in buildings \\
& Energy demand management and fuel poverty (nonphysical) \\
& Energy generation (renewables) \\
& District heating and smart grids \\
\hline \multirow{2}{*}{ Transportation } & Cycling and walking \\
& Public transportation and modal shift \\
& Smart travel and car pooling \\
\hline \multirow{2}{*}{ Land } & Densification of existing urban areas/urban infill \\
& Change of land use in response to local needs \\
\hline \multirow{2}{*}{ Water } & Water conservation \\
\hline Waste & Sustainable urban drainage \\
\hline Food & Waste recycling and reduction \\
\hline & Urban agriculture/allotments/locally resources food \\
Others & Urban biodiversity and “green” landscaping \\
& Use of local construction materials and contractors \\
& Taxation on consumption (non-physical) \\
& Behavioral “nudges” for more pro-environmental behavior (non-physical) \\
\hline
\end{tabular}

Table 2 Cultural quarters: success and factors necessary conditions [19].

\begin{tabular}{|c|c|}
\hline Factors & Necessary conditions \\
\hline \multirow{12}{*}{ Action } & The variety of secondary and primary land uses \\
\hline & Variety and extent of cultural venues \\
\hline & The attendance of an nightfall economy, involving the culture of cafe' \\
\hline & Forceof small-company economy, involving inspired businesses \\
\hline & Entrance to the education \\
\hline & The attendance of events and festivals \\
\hline & Workspaces' availability for artists as well as low-cost of the producers that are cultural \\
\hline & The economic development of small-firm within the cultural sectors \\
\hline & Controlled workspaces for the users of studio and office \\
\hline & Arts development's location concerns companies and agencies \\
\hline & Arts, education and media training \\
\hline & Evening uses and harmonizing daytime \\
\hline \multirow{7}{*}{ The form } & The urban morphology of Fine-grain \\
\hline & Adaptability and Variety of building stock \\
\hline & Streetscape’s permeability \\
\hline & Legibility \\
\hline & Quality and amount of communal space \\
\hline & Street frontages which are active \\
\hline & Individuals attractors \\
\hline \multirow{5}{*}{ The Meaning } & Gathering spaces and important meeting \\
\hline & Sense of progress and history \\
\hline & Imagery and area identity \\
\hline & The ability of knowledge \\
\hline & The environmental signifiers \\
\hline
\end{tabular}


combination of these constituents [19].

Consequently, an unsuitable urban shape will not consider a cultural quarter within the sense of being a high-quality place that attracts every visitor and user. This indicates that the quarters of culture and certainly the city creative economies' wider notion cannot be taken into account in separation from the characteristics and geography of urban places, the matters of place. Likewise, a cultural quarter with no meaning, inter alia, does not much the place. Nor will it is likely to be modern, or chiefly innovative. After all, culture is recognized as meaning. More willingly than this, cultural quarter that generates on the recent meaning-within the form of recent concepts, ideas and work [20].

A good quarter of culture, subsequently, will be reliable, however, also changing and innovative. A city economy, a good place, yet a personality enterprise will require preserving what is good, nevertheless to be highly adaptive and flexible as well as embrace transformation, recent ideas, recent methods of doing new work and things. Collapse for doing so will indicate that the quarter of culture will fade away completely, or become merely a group of openly funded facilities and venues, or else a symbol of previous culture-_heritage” [19].

A number of quarters concern culture will justify disappearing or ossifying with each other, in order to be taken above through further rival uses (apartments, offices) or to become a significant section of the heritage industry. The others may well carry on growing and developing to the future, even though achievement too has the ability to have its risk, wherever, the uses of low-value are driven out of the places that are successful. This conveys us to a mystery, in which, within a smallest amount, an amount of the activity discovered within the quarters of the culture may need governmental support for surviving within situ. Then, the issue becomes one of inspiring recent work, recent innovation and activity at the same time as harmonizing a wider mix of meanings, built forms and activities [21].

\subsection{Connecting "New Urban Economies" to Sustainable Urban Regeneration}

The clearest instance has to work with what is called "green economy" more solid with the activities connected to the building renovation and energy-efficiency. A great number of activities and services are essential to modernize a particular building, ranging from the materials of insulation, boilers and panels, to each of the connected service involving design services and architecture. Moreover, what attractive is that whilst the earlier has the ability to come from out of the country, the later is most frequently nearby sourced, consequently, there will be a great of economic power connected to the urban regeneration [22].

A small piece is less clear, however, attractive is the connection between the urban regeneration and digital economy; for instance, digital artifacts like smart meters frequently strengthen renewable energy distribution and production. Nevertheless, we can notice the driven solutions of the citizen [23].

The environmental regeneration's economic spill overt within the cities is likely to be to somewhat spontaneous; there is frequently modest action from the local government's side for making it occurred. However, I think that more planned action could improve the connections. For this to occur, the staff of the city needs to have the ability to work within the departments (for instance, economic, planning, social and environment) nevertheless interrelate with the other, the council and external stakeholders. Here, we notice, for instance, that the usefulness of companies with several business and technical expertise (however, with restricted understanding about the nature of a city), works on the ground, but in addition, communities of consumers and knowledge institutes are progressive. It is significant that various stakeholders are having the ability to be familiar with the views and the language of each other. The staff of the city could be significant 
mediators here, bridging the various players' interests. Besides, several cities have many ungraceful actions within these fields (for example, the strategies of smart city, energy and environmental plans, the deals of green economy, and regeneration policies) which could positively profit from more incorporation [15].

\subsection{Actual and Emerging Strategies for Improving Sustainability in Urban regeneration}

Sustainable development is a moving target: knowledge, technologies, and skills are being developed every day. Now, few integrated theories for achieving sustainability in the built environment can be identified. In fact, sustainability often relies on the management of transitions-a shift to doing things differently — that tends to be specific to each site, rather than a constant recipe or "one size fits all" type solution. The issue of sustainability is even more complex in the case of redevelopment or regeneration of existing urban areas. Redevelopment can be defined as "one or more public actions that are undertaken to stimulate activity when the private market is not providing sufficient capital and economic activity to achieve the desired level of improvement” [24].

This public action often involves measures such as direct public investment, capital improvements, enhanced public services, promotion, tax benefits and other stimuli including planning initiatives such as rezoning. This is slightly different from regeneration, defined as "a holistic process which aims to reverse the economic, social and physical decline of places where market forces alone will not suffice. The planning process provides the opportunity to enhance the role and capacity of communities as well as balancing community, business, environmental and individual needs. Effective regeneration requires active and meaningful long-term community engagement and involvement, as well as changes to the physical environment" [24].

With respect to the introduction of sustainability as a key-force for regeneration, one way of addressing the complexity of the task at hand, often used, is through certification standards. Certification programs can cover most of the aspects of urban property development, including setting targets for site decontamination, use of recycled materials, brownfield redevelopment, provision of public transport, options to discourage fossil transport use, energy consumption and efficiency in buildings, water recycling and waste management. As for policies, best-known directives at the moment concerning $\mathrm{CO}_{2}$ are energy performance directives. An example of the latter in the Netherlands is the EPC (Energy Performance Coefficient) directive [25].

Besides certification standards, sustainability approaches are often based on corporate responsibility theories. Some examples here are the "triple bottom line" approach [25], the "creating shared value" strategy [26] and "the natural step" [27].

In recent years, (local) governments have embarked on a passionate race to achieve climate goals before their neighbor. Largely due to incentives in public funding, cities have appropriated sustainability at large as a standard for competitiveness and means to attract various types of investment. Some international examples include "the Rotterdam Climate Initiative", "the 10 Melbourne Principles", "the Vancouver Climate Leadership" and "the Chicago Climate Action Plan” [28]. At building and project development level, the application of building certification programs is coming more and more to the forefront. Their purpose is to encourage measures in all possible areas of sustainable (re)development or even regeneration beyond actual design and construction, from the sourcing of materials to the management of a building (or area) once completed [24].

\section{Conclusions}

We have provided an overview of the key challenges for environmentally sustainable urban regeneration today from different angles of the "prism of sustainability”: physical/environmental (climate 
change, carbon emissions and resource use), social (social justice, inequality and health), and governance or "geo-institutional" (governance and geographical disparities). The economic dimension cuts across the previous three. All in all, these challenges tell us about the increasing complexity and interdependency of global and local processes. We can conclude that local regeneration has to consider its limits in terms of addressing macro-structural problems, while making an effective contribution to the wellbeing of local communities and being "part of the (global) solution" to our common environmental challenges.

In addition, a key issue in cities' context is the specific cultural and historical contexts of each city, which altogether shape their "room for manoeuvre" in the path towards environmental urban regeneration. In this sense, we need to start from the acknowledgement of different "starting points" in different cities, with some being relatively more "progressive" and others in what we can call a "stepping-up" process. We shall use this distinction in our analysis of concrete practices to be studied.

The discussion of economic drivers pointed to the potential of (public) investment and incentivisation to trigger environmental regeneration processes. Last but not least, the key role of policies and practices seeking to mainstream pro-environmental behavior amongst citizens and decision-makers in cities in order to achieve long-term environmental sustainability have been reviewed. Taken altogether, these approaches represent a menu of tools that have the potential to achieve effective and long-lasting environmentally sustainable urban regeneration in cities.

\section{References}

[1] McMichael, A. J. 2000. "The Urban Environment and Health in a World of Increasing Globalization: Issues for Developing Countries.” Bulletin of the World Health Organization 78 (9): 1117-26.

[2] Tong, S., Prapamontol, T., and Schirnding, Y. 2000. "Environmental Lead Exposure: A Public Health Problem of Global Dimensions.” Bulletin of the World Health Organization 9: 1068-77.
[3] Bulkeley, H. 2010. "Governing Climate Change in the City.” Urbanization and Global Environmental Change Viewpoints 4: 15-9.

[4] Johnson, C., Toly, N., and Schroeder, H. 2015. “The Urban Climate Challenge: Rethinking the Role of Cities in the Global Climate Regime.” The Social Sciences Humanities Research Council (Canada) under Grant: 205-21.

[5] Thompson, N., Kiefer, K., and York. J. G. 2011. "Distinctions Not Dichotomies: Exploring Social, Sustainable, and Environmental Entrepreneurship”. Social and Sustainable Entrepreneurship Advances in Entrepreneurship. Firm Emergence and Growth 13: 201-29.

[6] Korres, G. M., Kourliouros, E., Tsobanoglou, G. O., and Kokkinou, A. 2014. "Socio-economic Sustainability, Regional Development and Spatial Planning.” Presented at European and International Dimensions \& Perspectives, Mytilene, Lesvos, Greece.

[7] Larsen, J. N., and Engberg, L. A. 2011. “Organizational Change and Knowledge Management in Urban Regeneration Planning." Danish Journal of Geoinformatics and Land Management 46 (1): 114-26.

[8] Duguid, P. 2005. “The Art of Knowing: Social and Tacit Dimensions of Knowledge and the Limits of the Community of Practice." The Information Society 21: 109-18.

[9] Castanheira, G., and Mateus, L. B. R. 2013. "Defining Best Practices in Sustainable Urban Regeneration Projects.” Portugal SB13, Contribution of Sustainable Building to Meet EU 20-20-20 Targets.

[10] Turcu, C. 2012. "Local Experiences of Urban Sustainability: Researching Housing Market Renewal Intervention in Three English Neighbourhoods.” Progress in Planning 78 (3): 101-50.

[11] Salat, S., Labbé, F., and Nowacki, C. 2011. Cities and Forms-On Sustainable Urbanism. Paris: Hermann.

[12] Oliveira, P. J. A., and Balaban, O. 2013. “Climate Friendly Urban Regeneration: Lessons from Japan. Development \& Society: Asia, Climate Change, Urban Development.” United Nations University.

[13] Turcu, C. 2010. "Examining the Impact of Housing Refurbishment-Led Regeneration on Community Sustainability: A Study of Three Housing Market Renewal Areas in England.” Doctoral dissertation, London School of Economics and Political Sciences.

[14] United Nations. 2011. Population Distribution, Urbanization, Internal Migration and Development: An International Perspective. Department of Economic and Social Affairs Population Division

[15] URBACT. 2015. Sustainable Regeneration in Urban Areas. URBACT II Programme. 
[16] Carvalho, L. 2015. “New Urban Economies' to Sustainable Urban Regeneration.” University of Porto and UrbanIQ.

[17] Tosics, I. 2004. "European Urban Development: Sustainability and the Role of Housing." Journal of Housing and the Built Environment 19: 67-90.

[18] Cochrane, A. 2007. Understanding Urban Policy: A Critical Approach. Oxford, UK: Blackwell, 3-4.

[19] Montgomery, J. 2003. "Cultural Quarters as Mechanisms for Urban Regeneration. Part 1: Conceptualizing Cultural Quarters.” Planning, Practice \& Research 18 (4): 293-306.

[20] Landry, C. 2000. Creative Cities: A Toolkit for Urban Innovators. London: Earthscan.

[21] Bianchini, F., and Parkinson, M. C. 1996. Cultural Policy and Urban Regeneration: The West European Experience. Manchester: University of Manchester Press.

[22] LSE Cities. 2013. Stockholm: Green Economy Leader Report. A report by the Economics of Green Cities Programme at the London School of Economics and Political Science, London.
[23] Turcu, C., and Chaytor, S. 2015. The Impact of the Global Financial Crisis on European Cities. UCL Public Policy Briefing. University College London, London.

[24] Timmeren, A., Zwetsloot, J., Brezet, H., and Silvester, S. 2012. "Sustainable Urban Regeneration Based on Energy Balance.” Sustainability 4: 1488-509.

[25] Elkington, J. 1997. Cannibals with Forks: The Triple Bottom Line of 21st Century Business. Oxford, UK: Capstone Publishing Ltd.

[26] Porter, M. E., and Kramer, M. R. 2006. "The Link between Competitive Advantage and Corporate Social Responsibility-Strategy and Society.” Harvard Business Review 84 (12): 78-92.

[27] Robert, K. H. 1989. The Natural Step Story: Seeding a Quiet Revolution. Gabriola Island, Canada: New Society Publishers.

[28] Nelson, N. 2010. "Investigation into a Sustainable Implant in the Erasmusveld Neighborhood.” The Hague. Master thesis, WUR Wageningen, TU Delft, DSO, Municipality of Den Haag, The Netherlands. 